\title{
Antibiotic susceptibility of Helicobacter pylori isolates in Dakar, Senegal
}

\author{
Abdoulaye Seck ${ }^{1}$, Mouhamadou Mbengue ${ }^{2}$, Amy Gassama-Sow $^{3}$, Lamine Diouf ${ }^{2}$, Mouhamadou \\ Mourtalla $\mathrm{Ka}^{4}$, Cheikh Saad-Bouh Boye ${ }^{5}$ \\ 1 Laboratoire de Biologie Médicale, Institut Pasteur, Dakar Sénégal \\ 2 Service de Gastro-entérologie, Hôpital Arsitide Le Dantec, Dakar Sénégal \\ ${ }_{3}^{3}$ Laboratoire de Bactériologie Expérimentale, Institut Pasteur de Dakar, Dakar Sénégal \\ ${ }^{4}$ Service de Médecine Interne, Hôpital Arsitide Le Dantec, Dakar Sénégal \\ ${ }^{5}$ Laboratoire de Bactériologie-virologie, Hôpital Arsitide Le Dantec, Dakar Sénégal
}

\begin{abstract}
Background: Helicobacter pylori is the primary cause of peptic ulcer disease and an etiologic agent in the development of gastric cancer. A high frequency of $H$. pylori infection has been reported from resource-poor regions. $H$. pylori infection is curable with regimens of multiple antimicrobial agents. However, antibiotic resistance is a leading cause of treatment failure. In Africa, there are very little data concerning the susceptibility of $H$. pylori isolates to antibiotics.

Methodology: H. pylori isolates from gastric biopsies from outpatients $\geq 18$ years old affected by a gastro-duodenal ulcer were used in this study. Susceptibility testing was performed for amoxicillin, ciprofloxacin and metronidazole by using the Epsilometer test (E-test) method.

Results: $H$. pylori strains were isolated from 40 patients of whom 36 were diagnosed as having duodenal ulcer, two with gastric ulcer, and two with gastro-duodenal ulcer. Thirty-six (90\%) of the isolates were resistant to metronidazole (MICs $\geq 8 \mu \mathrm{g} / \mathrm{l})$, whereas all isolates were susceptible to amoxicillin (MICs $\leq 0.5 \mu \mathrm{g} / \mathrm{ml}$ ) and ciprofloxacin $(\mathrm{MICs} \leq 1 \mu \mathrm{g} / \mathrm{ml}$ ).

Conclusion: These data suggest that metronidazole should not be used therapeutically among Senegalese patients in first-line therapy, while ciprofloxacin could be recommended in association with amoxicillin and a proton pump inhibitor in Senegal.
\end{abstract}

Keywords: Helicobacter pylori; antimicrobial susceptibility; Senegal

J Infect Developing Countries 2009; 3(2):137-140.

Received 29 February 2008 - Accepted 3 September 2008

Copyright (C) 2009 Seck et al. This is an open-access article distributed under the Creative Commons Attribution License, which permits unrestricted use, distribution, and reproduction in any medium, provided the original work is properly cited.

\section{Introduction}

The frequency of $H$. pylori infection is rising worldwide [1]. The problem is more acute in the resource-poor regions, particularly in Africa [2]. The hospital prevalence rate of $H$. pylori infection in Senegal is as high as $82 \%$ [3]. To date, the eradication of $H$. pylori infection is clearly indicated for healing gastro-duodenal ulcerous disease, not only because it modifies the disease's natural course [4], but because it also prevents long-term ulcer relapse [5]. The successful treatment for eradication of $H$. pylori infection requires a proton pump inhibitor (PPI) and a combination of two or more antibiotics, depending on the susceptibility of isolates to antibiotics [6]. As the treatment of the infection starts with a standard therapeutic regimen, it is therefore important to know in advance the resistance rates of isolates to antibiotics commonly used in the treatment. In Africa, there are very little data concerning the susceptibility of $H$. pylori isolates to antibiotics, even considering that the resistance rates should be high [7].

The aim of this study was to assess the susceptibility of $H$. pylori strains isolated from gastric biopsies of patients with ulcer to antibiotics commonly used in therapeutic procedures.

\section{Materials and methods}

Patients and Bacterial isolates

This is a prospective study including outpatients $\geq 18$ years old selected between January 1999 and June 2000, and consulting at the gastroenterology department of the major teaching hospital Aristide Le Dantec in Dakar. This study involved patients with clinical symptoms which required a digestive endoscopy. Written and informed consent was obtained from all patients, and all aspects of the study 
were approved by the ad hoc Ethical Committee. No patient had taken antibiotics, proton pump inhibitors (PPIs), or non-steroidal anti-inflammatory drugs a month before their inclusion in the study. During the digestive endoscopy, in the presence of duodenal ulcer or gastric ulcer or gastro-duodenal ulcer, gastric biopsies were conducted. Four biopsy specimens (two specimens from different sites of the antrum gastric and two specimens from different sites of the fundus gastric) were obtained from each patient after a digestive endoscopy. Biopsy specimens were stored and transported in tubes containing $0.5 \mathrm{ml}$ of PBS (phosphate buffered saline). Samples were crushed in $0.5 \mathrm{ml}$ of PBS and cultured in Wilkins Chalgren Agar (Becton Dickinson, Heidelberg, Germany) containing $5 \%$ to $10 \%$ horse blood, vancomycin $(10 \mathrm{mg} / \mathrm{l})$ (Sigma-Aldrich, Steinheim, Germany), and trimethoprim (5 mg/l) (Sigma-Aldrich, Steinheim, Germany). We used only one isolate from each patient for our analysis. Culture media were incubated for a period of up to 12 days in a microaerophilic atmosphere $\left(5 \% \mathrm{O}_{2}, 10 \% \mathrm{CO}_{2}\right.$, and $85 \% \mathrm{~N}_{2}$ ) at $37^{\circ} \mathrm{C}$, and were daily examined for bacterial growth.

Thus, forty strains isolated from gastric biopsies from adult patients affected by an ulcer were used in this study. Isolates were stored at $-80^{\circ} \mathrm{C}$ in $20 \%$ glycerol-brain hearth infusion.

\section{Identification of $\mathrm{H}$. pylori isolates}

H. pylori isolates were identified by colonial morphology, characteristic spiral morphology on Gram staining, and positive findings for catalase, urease and oxidase tests.

\section{Antimicrobial susceptibility testing}

Susceptibility to antibiotics testing was performed via minimum inhibitory concentration (MIC) determination by E-test ${ }^{\circledR}$ (AB biodisk, Solna, Sweden) for amoxicillin, metronidazole, and ciprofloxacin according to the recommendations of Megraud et al. [8]. The tested inoculum was adjusted to a turbidity of 3 to 4 MacFarland standard. Sterile swabs were used to inoculate plates of Wilkins Chalgren Agar (Becton Dickinson, Heidelberg, Germany) containing 5\% to $10 \%$ horse blood. After 72 hours of incubation at $37^{\circ} \mathrm{C}$ in microaerophilic atmosphere $\left(5 \% \mathrm{O}_{2}, 10 \% \quad \mathrm{CO}_{2}\right.$, and $\left.85 \% \mathrm{~N}_{2}\right)$, the MIC of each antibiotic was determined. Quality control was performed using H. pylori ATCC 43504. The breakpoints used to define the resistance were as follows: metronidazole ( $>8 \mu \mathrm{g} / \mathrm{ml}$ ), amoxicillin ( >
$0.5 \mu \mathrm{g} / \mathrm{ml}$ ) and ciprofloxacin ( > $1 \mu \mathrm{g} / \mathrm{ml}$ ) [8,9]. Data processing was performed using WHONET $\mathrm{V}$ software.

\section{Results}

Forty H. pylori strains were isolated from 40 patients of whom 36 were diagnosed as having duodenal ulcer, two with gastric ulcer and two with gastro-duodenal ulcer. All tested isolates were susceptible to amoxicillin $\left(\mathrm{MIC}_{90} 0.25 \mu \mathrm{g} / \mathrm{ml}\right.$ ) and ciprofloxacin $\left(\mathrm{MIC}_{90} 0.38 \mu \mathrm{g} / \mathrm{ml}\right)$. MIC values varied from 0.023 to $0.5 \mu \mathrm{g} / \mathrm{ml}$ for amoxicillin, and from 0.004 to $0.5 \mu \mathrm{g} / \mathrm{ml}$ for ciprofloxacin.

Metronidazole had a reduced activity $\left(\mathrm{MIC}_{50} 32\right.$ $\mu \mathrm{g} / \mathrm{ml}) ; 90 \%$ of the isolates $(\mathrm{n}=36)$ were resistant to this compound; and MIC values varied from 0.125 to $>256 \mu \mathrm{g} / \mathrm{ml}$. The $\mathrm{MIC}_{50}$ and $\mathrm{MIC}_{90}$ of each antibiotic are shown in Table 1.

Table 1. $\mathrm{MIC}_{50}$ and $\mathrm{MIC}_{90}(\mu \mathrm{g} / \mathrm{ml})$ of amoxicillin, ciprofloxacin, and metronidazole for $\mathrm{H}$. pylori isolates.

\begin{tabular}{llll}
\hline \multirow{2}{*}{ Antibiotics } & \multicolumn{2}{l}{ MIC $(\mu \mathrm{g} / \mathrm{ml})$} & \\
\cline { 2 - 4 } & MICs range & MIC $_{50}$ & MIC $_{90}$ \\
\hline Amoxicillin & $0.023-0.5$ & 0.125 & 0.25 \\
Ciprofloxacin & $0.004-0.5$ & 0.125 & 0.38 \\
Metronidazole & $0.125->256$ & 32 & $>256$ \\
\hline
\end{tabular}

\section{Discussion}

In this study, MICs of three antibiotics (amoxicillin, ciprofloxacin, and metronidazole) were determined for $H$. pylori isolates from Senegal. The study showed that all isolates were susceptible to amoxicillin and ciprofloxacin, whereas the metronidazole resistance rate was high $(90 \%$ of the isolates).

No resistance to amoxicillin was found, and MICs ranged from 0.003 to $0.5 \mu \mathrm{g} / \mathrm{ml}$.

Usually, MICs of amoxicillin for $H$. pylori are very low $(0.03 \mu \mathrm{g} / \mathrm{ml})$; nevertheless, in our study, we found some sensitive isolates with a reduced susceptibility (MICs: $0.25-0.50 \mu \mathrm{g} / \mathrm{ml}$ ), as described by Megraud et al. [8]. In many countries, no amoxicillin-resistant $H$. pylori has been detected until now $[10,11]$. However, there have been recent reports of resistance to this antibiotic. In Europe and in the USA, resistance rates are less than $1 \%$, indicating that it is not yet a problem and antimicrobial susceptibility testing for this drug is not currently needed clinically $[12,13]$. By contrast, high resistance rates have been reported in some studies 
from other parts of the world: $18.5 \%$ in South Korea [14], 19.4\% in Indonesia [15], 32.8\% in India [16], and $38 \%$ in Brazilia [17]. In a study conducted in IleIfe, southwest of Nigeria, $100 \%$ of 32 isolates were resistant [18].

In our study, MIC of ciprofloxacin was averaging $0.38 \mu \mathrm{g} / \mathrm{ml}$; this value is comparable to the one found by Glocker et al. in Germany in 2005 [19]. Quinolone resistance has been described with variable resistance rates. Indeed, low resistance rates were reported in some countries: $1 \%$ in India [16], $2 \%$ in Egypt [20], 5\% in the south-west of Nigeria [18], 6\% in Bulgaria [9], and 6.9\% in Indonesia [15]. In Germany, ciprofloxacin resistance rate reached $11.2 \%$ in 2003 , increased to $16.6 \%$ in 2004 , and further increased to $22.1 \%$ in 2005 [19]. In South Korea, a high resistance rate of $33.8 \%$ has been reported in strains isolated from adult patients [14]. The good susceptibility of $H$. pylori to ciprofloxacin suggests that this antibiotic might be an alternative drug in the regimen treatment for eradication of $H$. pylori in gastro-duodenal ulcerous disease in Senegal.

Ninety percent $(90 \%)$ of isolates were resistant to metronidazole with a MIC $>8 \mu \mathrm{g} / \mathrm{ml}$. A high level of resistance $(100 \%)$ was found in Egypt in paediatric patients [20], in the southwest of Nigeria [18], and in Indonesia [15]. Resistance rates of $77.9 \%, 70 \%$ and $66.2 \%$ were reported in India, in Kuwait, and in South Korea respectively $[11,14,16]$. Elsewhere, variable resistance rates were described: $15.8 \%$ in Bulgaria [9], 25.1\% in the USA [13], and 55\% in Brazilia [17]. However, resistance rates to metronidazole may vary within a country. For example, in India, the resistance rate to metronidazole was high in Lucknow, Chennai and Hyderabad (68\%, 88.2\% and 100\%, respectively), whereas a moderate rate was observed in Delhi (37.5\%) and Chandigarh (38.2\%) [16]. In Europe, according to the studies conducted between 19892001 and 1990-2002 respectively, the resistance rates varied between $16.0 \%$ and $43 \%$ in paediatric patients and between $14.9 \%$ and $40.3 \%$ in adults patients [12]. Moreover, it seems that the primary resistance to nitro-imidazole is related to the frequency of these compounds used in the treatment of other infections. In developing countries, high estimated resistance rates (more than 60\%) might be connected to the frequency of treatment by nitroimidazole in the digestive and genital parasitoses [7]. The use or abuse of this inexpensive drug may contribute to the increase of metronidazole resistance. In addition, testing conditions, including choice of medium, age of the colonies, incubation period and conditions, and inoculum size, have been shown to influence the results of susceptibility testing for metronidazole [12]. Overall, none of the methods was found reliable for testing the susceptibility of $H$. pylori to metronidazole because there is a lack of reproducibility [21].

Our results showed a high resistance rate to metronidazole; however, no amoxicillin and ciprofloxacin resistance were observed. On the basis of our findings, metronidazole should not be used therapeutically among Senegalese patients in firstline therapy. Amoxicillin should be the first choice antibiotic and ciprofloxacin should replace metronidazole in the eradication treatment of gastroduodenal ulcers with $H$. pylori infection in Senegal. Thus amoxicillin should be recommended in association with ciprofloxacin and a proton pump inhibitor in Senegal. Considering the increasing resistance rate in many countries, monitoring of susceptibility of $H$. pylori to antibiotics appears to be necessary in the choice of effective therapy in order to eradicate $H$. pylori infections and to optimize the regimen in case of treatment failure.

\section{Acknowledgments}

We thank Ibrahima Bahsoun and Alfred Dieudonne Kinana for critical reading of the manuscript. This work was financed from own funds by the Service de Gastro-enterologie and the Laboratoire de Bactériologie-virologie, Hôpital Arsitide Le Dantec, Dakar Sénégal. This work was carried out in the Laboratoire de Bactériologie-virologie, Hôpital Arsitide Le Dantec, Dakar Sénégal

\section{References}

1. Blaser MJ (1997) Ecology of Helicobacter pylori in the human stomach. J Clin Invest 100:759-762.

2. Holocombe C, Ouattara BA, Elridge J, Jones DM (1992) Helicobacter pylori, the most common bacterial infection in AFRICA: a random serological study. Am J Gastroenterol 87: 28-30.

3. Mbaye PS, Fall F, Michel G, Klotz F (1998) Etude de l'éradication d'Helicobacter pylori chez des malades sénégalais atteints d'ulcère duodénal. Acta Endoscopica 28 Suppl 3: 285.

4. Graham DY and Go MF (1993) Helicobacter pylori: current status. Gastroenterology 105: 279-82.

5. Graham DY, Lew GM, Klein PD, Evans DG, Evans DJ Jr, Saeed ZA, Malaty HM (1992) Effect of treatment of infection Helicobacter pylori on the long-term recurrence of gastric or duodenal ulcer: a randomized controlled study. Ann Int Med 116: 705-8.

6. NIH Consensus Development Panel on Helicobacter pylori in Peptic Ulcer Disease (1994) NIH, Consensus, and Conference: Helicobacter pylori in peptic ulcer disease. JAMA 272:65-9. 
7. Glupczynski Y, Burette A, De Koster E, Nyst JF, Deltenre M, Cadranel S et al. (1990) Metronidazole resistance in Helicobacter pylori. Lancet 335: 967-7.

8. Megraud F, Lehn N, Lind T, Bayerdörffer E, O'Morain C, Spiller R et al. (1999) Antimicrobial susceptibility testing of Helicobacter pylori in a large multicenter trial: the MACH 2 study. Antimicrob Agents Chemother 43: 2747-2752.

9. Boyanova L, Koumanova R, Gergova G et al. (2002) Prevalence of resistant Helicobacter pylori isolates in Bulgarian children. J Med Microbial 51: 786-790.

10. Kalach N, Serhal L, Asmar E, Campeotto F, Bergeret M, Dehecq E, Spyckerelle C, Charkaluk ML, Decoster A, Dupont C, Raymond J ( 2007) Helicobacter pylori primary resistant strains over 11 years in French children. Diagn Microbiol Infect Dis 59:217-22.

11. Albert JM, Al-Mekhaizeem K, Neil L, Dhar R, Dhar PM, Al-Ali M, Al-Abkal HM, Haridas S (2006) High prevalence and level of resistance to metronidazole, but lack of resistance to other antimicrobials in Helicobacter pylori, isolated from a multiracial population in Kuwait. Aliment Pharmacol Ther 24:1359-66.

12. Megraud F (2004) $H$. pylori antibiotic resistance: prevalence, importance, and advances in testing. Gut 53:1374-1384

13. Duck WM, Sobel J, Pruckler JM, Song Q, Swerdlow D, Friedman C, Sulka A, Swaminathan B, Taylor T, Hoekstra M, Griffin P, Smoot D, Peek R, Metz DC, Bloom PB, Goldschmidt S, Parsonnet J, Triadafilopoulos G, PerezPerez GI, Vakil N, Ernst P, Czinn S, Dunne D, Gold BD (2004) Antimicrobial resistance incidence and risk factors among Helicobacter pylori-infected persons, United States. Emerg Infect Dis 10:1088-94.

14. Kim JM, Kim JS, Kim N, Kim SG, Jung HC, Song IS (2006) Comparison of primary and secondary antimicrobial minimum inhibitory concentrations for Helicobacter pylori isolated from Korean patients. Int $\mathbf{J}$ Antimicrob Agents 28:6-13.

15. Kumala W and Rani A (2006) Patterns of Helicobacter pylori isolate resistance to fluoroquinolones, amoxicillin, clarithromycin and metronidazole. Southeast Asian J Trop Med Public Health 37:970-4.
16. Thyagarajan SP, Ray P, Das BK, Ayyagari A, Khan AA, Dharmalingam S, Rao UA, Rajasambandam $P$, Ramathilagam B, Bhasin D, Sharma MP, Naik SR, Habibullah CM (2003) Geographical difference in antimicrobial resistance pattern of Helicobacter pylori clinical isolates from Indian patients: Multicentric study. J Gastroenterol Hepatol 18:1373-8.

17. Godoy APO, Ribeiro ML, Benvengo YH, Vitiello L, Miranda Mde C, Mendonça S, Pedrazzoli J Jr (2003) Analysis of antimicrobial susceptibility and virulence factors in Helicobacter pylori clinical isolates. BMC Gastroenterol 11: 3:20.

18. Abordin OA, Abdu AR, Odetoyin BW, Okeke IN, Lawal OO, Ndububa DA, Agbakwuru AE and Lamikanra A (2007) Antibiotic resistance of Helicobacter pylori from patients in Ile-Ife, South-west, Nigeria. African Health Science 7: 143147.

19. Glocker E, Stueger HP, Kist M (2007) Quinolone resistance in Helicobacter pylori isolates in Germany. Antimicrob Agents Chemother 51:346-9.

20. Sherif M, Mohran Z, Fathy H, Rockabrand DM, Rozmajzl PJ, Frenck RW (2004) Universal high-level primary metronidazole resistance in Helicobacter pylori isolated from children in Egypt. J Clin Microbiol 42 Suppl 10:483234.

21. Glupczynski Y, Broutet N, Cantagrel A, Andersen LP, Alarcon T, López-Brea M, Megraud F

(2002) Comparison of the E test and agar dilution method for antimicrobial susceptibility testing of Helicobacter pylori. Eur J Clin Microbiol Infect Dis 21:549-52. .

\section{Corresponding Author}

Abdoulaye Seck, Laboratoire de Biologie Médicale, Institut Pasteur de Dakar, BP: 220, Dakar Sénégal Tel: +221 3383992 00; Fax: +2213382270 52 Email: seck@pasteur.sn

Conflict of interest: No conflict of interest is declared. 